\title{
Ocular Application of Nerve Growth Factor Protects Degenerating Retinal Ganglion Cells in a Rat Model of Glaucoma
}

\author{
Valeria Colafrancesco, PhD, ${ }^{*}$ Vincenzo Parisi, MD, PhD, ${ }^{*}$ Valentina Sposato, BSc, $\dagger$ \\ Simona Rossi, PhD, $\dagger$ Matteo Antonio Russo, MD, PhD, $\ddagger$ Marco Coassin, MD, PhD, $\S$ \\ Alessandro Lambiase, MD, PhD, $\S$ and Luigi Aloe, PhD $\dagger$
}

\begin{abstract}
Purpose: Elevated intraocular pressure is a crucial pathologic event for the development of glaucoma (GL). We have reported that nerve growth factor (NGF) reaches retinal cells and the optic nerve $(\mathrm{ON})$ when applied to the eye. Whether ocular application of NGF prevents or reduces damage to retinal ganglion cell (RGC) is not known.
\end{abstract}

Methods: GL was induced in adult rats by the injection of hypertonic saline into the episcleral vein of the right eye and the left eye used as control. Rats were then treated daily with ocular application of NGF or vehicle solution for 7 weeks. Retinal and ON tissues were then used for structural, immunohistochemical, and biochemical studies.

Results: The injection of hypertonic saline into the episcleral vein led to progressive degeneration of RGCs, with the loss of nearly $40 \%$ of these cells after 7 weeks of treatment. This cellular loss is associated with the downregulation of NGF and NGF-receptor expression in the retina and $\mathrm{ON}$ of the glaucomatous eye and ocular treatment with NGF significantly reduced the deficit induced by GL.

Conclusions: These findings indicate that NGF can exert protective action on RGC degeneration occurring in glaucomatous retina. We suggest that ocular NGF treatment might be a suitable pharmacologic approach to investigate protective mechanisms of degenerating RGCs.

Key Words: glaucoma (GL), intraocular pressure (IOP), NGFreceptor, neurotrophins, retinal ganglion cell (RGC)

( J Glaucoma 2010;00:000-000)

G laucoma (GL) is the second leading cause of blindness worldwide and the prevalence of this disease is expected to grow as the population ages. ${ }^{1}$ GL is a disease

Received for publication July 24, 2009; accepted January 31, 2010.

From the *Department of Ophthalmology, IRCCS, G.B. Bietti Eye Foundation; IInstitute of Neurobiology and Molecular Medicine, Section of Neurobiology, National Research Council (CNR); †IRCCS San Raffaele Pisana; and §Department of Ophthalmology, University of Rome "Campus Bio-Medico," Rome, Italy.

This study was supported by G.B. Bietti Eye Foundation and PRIN prot. No. 2007AF3XH4_005 to Luigi Aloe, by "Fondazione Cassa di Risparmio di Roma" and "Ministero della Salute" Grant No. RF-FGB-2005-150198.

Reprints: Luigi Aloe, PhD, Institute of Neurobiology and Molecular Medicine, Section of Neurobiology, National Research Council (CNR), Via del Fosso di Fiorano 64/65, 00143 Rome, Italy (e-mail: luigi.aloe@inmm.cnr.it).

Copyright (C) 2010 by Lippincott Williams \& Wilkins

DOI:10.1097/IJG.0b013e3181d787e5 characterized by progressive death of the retinal ganglion cells (RGCs) leads to optic nerve (ON) degeneration and vision loss. However, although the elevated intraocular pressure (EIOP) is considered a primary cause of the visual deficit, it is known that some patients still experience visual loss after lowering the IOP and others with GL and ON degeneration can have normal IOP. ${ }^{2-4}$ Despite these evidence, a major therapeutic aim is to facilitate the survival of RGCs through pharmacologic or surgical reduction of IOP. ${ }^{5-8}$ These and other observations have led to the hypothesis that degeneration of retinal cells may result from a secondary insult induced by alterations in the neuronal environment, such as changes in neurotransmitters, influx of calcium into the cells, formation of free radicals, or depletion of neurotrophic factors. ${ }^{5-8}$

Nerve growth factor (NGF) is the first identified and best-characterized neuroprotective molecule, acting upon and produced by a number of cells within and outside the nervous system. ${ }^{9-11}$ The biologic activity of NGF is regulated by 2 different types of receptors that are located on the surface of responsive cells: the high-affinity NGFreceptor (TrkA), which belongs to the family of tyrosine kinase receptors, and the low-affinity NGF-receptor (p75), which is a transmembrane glycoprotein that lacks a tyrosine kinase domain. ${ }^{12,13}$ There is now a number of studies demonstrating that NGF is able to exert a wide spectrum of effects also on cells of the visual system, playing a crucial role in promoting the survival and growth of retinal cells. Thus, abnormal presence of NGF or its receptors can lead to cell death, not only in the central and peripheral nervous system, ${ }^{9-11}$ but also in the visual system in vivo ${ }^{14-22}$ and in vitro. ${ }^{23,24} \mathrm{NGF}$ promotes the functional recovery of RGCs in an animal model of ocular ischemia, ${ }^{16-21}$ reduces retinal cell damage induced by intraocular hypertension, ${ }^{19}$ and delays retinal cell degeneration in rodents with retinitis pigmentosa. ${ }^{17}$ The functional role of NGF on retinal cells is supported by studies showing that intravitreal injection of NGF increases RGC survival and that eye NGF deprivation is known to lead to RGC death. ${ }^{19}$ One primary obstacle to clinical testing of NGF for retinal disorders is, however, the lack of an efficient, noninvasive means to deliver this factor in the posterior segment of the eye to the target cells. We have recently reported that intraocular administration of radiolabeled NGF binds to RGCs and $\mathrm{ON}$ axons $^{25}$ and that conjunctival applied NGF reaches retinal cells and brain NGF-receptive neurons. ${ }^{26,27}$ These observations suggested to investigate whether eye application of NGF protects retinal cells degeneration in a rat model of GL induced by EIOP in adult rats. The results of 
these studies indicate that GL induced in rats with EIOP reduces significantly the presence of NGF and the number of RGCs and ON axons, whereas ocular NGF administration significantly protects these degenerative events.

\section{METHODS}

\section{Animals and Surgical Procedures}

GL was induced in pathogen-free adult male SpragueDawley rats $(\mathrm{n}=94)$, after anesthesia (ketamine $100 \mathrm{mg} / \mathrm{mL}$; xylazine $20 \mathrm{mg} / \mathrm{mL}$; and acepromazine $10 \mathrm{mg} / \mathrm{mL}$ ). Briefly, as described by Morrison et al, ${ }^{28}$ after a lateral canthotomy, a small plastic ring was fitted around the globe, straddling the equator and oriented to provide unobstructed passage for one radial aqueous vein in the superior quadrant of the eye, and then rats received $50 \mu \mathrm{L}$ sterile hypertonic saline solution $(1.75 \mathrm{M} \mathrm{NaCl})$ into the superior episcleral vein of the right eye. All animals were maintained in a 12 hours (06:00 to 18:00) light: dark cycle. The right eye was indicated as the glaucomatous eye and the left eye was indicated as control eye. Operated rats were divided into 2 groups and housed in single cages in a constant low-light environment (40 to $901 \mathrm{~lx}$ ) to minimize IOP circadian oscillations. IOP was measured weekly with the TonoPen XL tonometer (Medtronic Ophthalmics, Jacksonville, FL) under topical anesthesia. IOP is reported as the mean of 10 valid readings per eye. Mean changes were calculated for each eye \pm SEM. The housing, care, and experimental procedures involving the experimental rats were carried out in accordance with the guidelines set by the Association for Research in Vision and Ophthalmology Statement for the Use of Animals in Ophthalmic and Vision Research and by local Ethical Commission on Animal Experimentation.

\section{Animal Treatments}

NGF was purchased from Biolab (Rome, Italy) or purified from adult male mouse submandibular glands following the method of Bocchini and Angeletti. ${ }^{29}$ Purified NGF was dissolved in $0.9 \% \mathrm{NaCl}$ phospate $(200 \mu \mathrm{g} / \mathrm{mL})$ and kept at $4{ }^{\circ} \mathrm{C}$ for no longer than 1 week. Under these conditions, both stability and activity remained unchanged. Rats $(n=42)$ received topical ocular administration of $20 \mu \mathrm{L}$ vehicle solution, consisting of $0.9 \% \mathrm{NaCl}$, twice a day in both the right glaucomatous eye (GLV) and the left non-glaucomatous control eye (CV) for 7 weeks.

A second group of rats $(n=42)$ received topical ocular administration of $20 \mu \mathrm{L}$ of this NGF solution $(4 \mu \mathrm{g}$ of purified NGF) 2 times a day for 7 weeks in the right glaucomatous eye (GLNGF) and the left control eye (CNGF). Animals were sacrificed with an overdose of Nembutal at time $0,1,3$, and 7 weeks after the induction of GL.

\section{Histologic Analysis of the Retina}

For light histologic analysis of the retina, 5 eyes with attached ON were removed from 5 different animals of each experimental group $(n=4)$, fixed in Bouin fluid for 1 week, and then immersed in phosphate-buffered saline (PBS), pH 7.4, containing $20 \%$ sucrose for 3 days as described earlier. ${ }^{26}$ Coded sections of the eyes were cut at $20 \mu \mathrm{m}$ with a cryostat (Leica CM $1850 \mathrm{UV}$, Germany) at $-20^{\circ} \mathrm{C}$, taking care that the cross sections of each retina were performed in the same orientation. Sections were then stained with hematoxylin-eosin. The number of RGCs were counted under a Zeiss microscope equipped with a
$40 \times$ objective. To obtain representative data regarding the number of RGCs, RGC counts were performed on 5 random areas, located approximately $2 \mathrm{~mm}$ from the centre of the optic disc, of 6 different sections of each retina. All counts were performed in a masked manner and the results were averaged and converted to cells $/ \mathrm{mm}^{2}$.

\section{Ultrastructural Analysis of the $\mathrm{ON}$}

The ON, located $1 \mathrm{~mm}$ from the adjacent retina, was dissected out, was fixed in $4 \%$ paraformaldehyde in $0.1 \mathrm{M}$ PBS, $\mathrm{pH} 7.4$, for 24 hours and then post-fixed in $1 \% \mathrm{OsO}_{4}$ for 4 hours, dehydrated with ascending ethanol, and then embedded in 812/Spurr's low viscosity resin. ON sections were cut with a Reichert microtome, collected on 200 mesh grids, stained with uranyl-acetate and lead citrate, observed under a Philips 100 electron microscope, and photographed. The presence of degenerating axons in 10 randomly selected fields, $50 \times 80 \mu \mathrm{m}$, of each section $(n=6)$ of $\mathrm{ON}$ of each experimental group $(n=4)$, was examined and the number of axons with degenerating axon profiles, displaying myelin swelling and irregular debris, was counted in a masked manner and compared.

\section{NGF-receptor Immunohistochemistry}

Eyes were fixed overnight in $4 \%$ paraformaldehyde in $0.1 \mathrm{M}$ PBS, $\mathrm{pH} \mathrm{7.4,} \mathrm{and} \mathrm{then} \mathrm{left} \mathrm{overnight} \mathrm{in} 0.1 \mathrm{M}$ PBS containing $20 \%$ sucrose. Coded $15-\mu \mathrm{m}$ thick sections of each retina were cut with a cryostat at $-20^{\circ} \mathrm{C}$ and immunostained with anti-TrkA (1:70; Upstate, Temecula, CA) and anti-p75 antibodies, previously produced. ${ }^{27}$ For quantitative analyses, we counted labeled RGCs in 12 different areas $\left(10.0 \times 10^{2} / \mathrm{mm}^{2}\right.$ each $)$ of each retina, located approximately $300 \mu \mathrm{m}$ from the centre of the optic disk, using a Zeiss microscope, equipped with a computerized image analysis system and a controlled motorized stage (IAS 2000, Delta Sistemi, Roma, Italy). The number of TrkA and p75 immunostained RGCs was defined as the percentage of immunostained cells compared with CV. All counts were performed in a masked manner.

\section{Western Blotting}

Retinal tissues were isolated and immediately sonicated. Tissue samples were homogenized in buffer $(10 \mathrm{mM}$ Tris-acetate, $\mathrm{pH} 7.4 ; 100 \mathrm{mM} \mathrm{NaCl} ; 1 \mathrm{mM}$ ethylenediamine-tetraacetic acid; $1 \mathrm{mM}$ ethyleneglycol-tetraacetic acid; $1 \%$ Triton X-100; $10 \%$ glycerol; $0.1 \%$ sodium-dodecylphosphate, SDS; $20 \mathrm{mM} \mathrm{Na} \mathrm{P}_{2} \mathrm{O}_{7} ; 2 \mathrm{mM}$ sodium-orthovanadate, $\mathrm{Na}_{3} \mathrm{VO}_{4} ; 1 \mathrm{mM} \mathrm{NaF} ; 2 \mu \mathrm{g} / \mathrm{mL}$ aprotinin; $1 \mathrm{mM}$ phenylmethylsulfonyl fluoride; and $1 \mu \mathrm{g} / \mathrm{mL}$ leupeptin) at $4^{\circ} \mathrm{C}$. After $12,000 \mathrm{rpm}$ centrifugation for 20 minutes the supernatants were submitted to western blotting. Samples ( $30 \mu \mathrm{g}$ of total protein) were dissolved in loading buffer $(0.1 \mathrm{M}$ Tris- $\mathrm{HCl}$ buffer, $\mathrm{pH} 6.8$, containing $0.2 \mathrm{M}$ dithiothreitol, 4\% SDS, $20 \%$ glycerol, and $0.1 \%$ bromophenol blue), separated by $8 \%$ or $12 \%$ SDS-polyacrylamide gel electrophoresis, and electrophoretically transferred to polyvinylidine diflouride membrane overnight. The membranes were incubated for 1 hour at room temperature with blocking buffer constituted by $5 \%$ non-fat dry milk in TBS-T (10 mM Tris, $\mathrm{pH} 7.5,100 \mathrm{mM} \mathrm{NaCl}$, and $0.1 \%$ Tween-20). Membranes were washed 3 times for 10 minutes each at room temperature in TBS-T followed by incubation at $4{ }^{\circ} \mathrm{C}$ with primary antibodies overnight (anti-TrkA and anti p75 antibodies purchased from SantaCruz, CA and anti- $\beta$-actin from SIGMA, St Louis). Membranes were washed 3 times 
for 10 minutes each at room temperature in TBS-T and incubated for 1 hour with horseradish peroxidase (HRP)conjugated anti-rabbit IgG or HRP-conjugated anti-mouse $\mathrm{IgG}$ as the secondary antibody (Cell Signaling Technology, MA). The blots were developed with an enhanced chemiluminescent HRP substrate as the chromophore (Millipore, MA). The public Image J Software was used to evaluate band density, which was expressed as arbitrary units of grey level. The Image $\mathbf{J}$ program determines the optical density of the bands using a grey scale shareholding operation. The optical density of $\beta$-actin bands was used as a normalizing factor. For each gel per blot, the normalized values were then expressed as percentage of relative normalized controls and used for statistical evaluation. Statistical evaluations were performed using the StatView package for Windows. The data are expressed as mean$\mathrm{s} \pm \mathrm{SEM}$. TrkA and p75 protein concentrations determined by western blot analyses were evaluated by computing analyses of variance. A $P$ value of less than 0.05 was considered significant.

\section{Analysis of Cell Death}

For the determination of RGC death and survival, sections of the retina were immunostained with terminal deoxynucleotidyl transferase-mediated deoxyuridine triphosphate-biotin nick-end labeling (TUNEL), a marker of apoptotic cell deat. ${ }^{30}$ Briefly, retinal sections were first incubated in a blocking solution $\left(3 \% \mathrm{H}_{2} \mathrm{O}_{2}\right.$ in methanol) for 10 minutes at 15 to $25^{\circ} \mathrm{C}$, incubated in a permeabilization solution containing PBS $1 \times$ with $0.1 \%$ Triton X-100 for 2 minutes at $4{ }^{\circ} \mathrm{C}$, and then labeled with an in-situ cell death detection kit (Roche Diagnostic, Boheringer, Mannheim, Germany) according to the manufacturer's instructions. DNA strand breaks were labeled and visualized with $0.4 \%$ diaminobenzidine- $\mathrm{H}_{2} \mathrm{O}_{2}$. TUNEL-positive cells with nuclear condensation or fragmentation were considered as apoptotic cells. The number of TUNELstained cells was expressed as RGCs per $\mathrm{mm}^{2}$.

\section{NGF Determination}

Retinas from 24 animals $(n=6$ retinas per each experimental group) were homogenized by ultrasonication in extraction buffer $(10 \mathrm{mM}$ Tris-acetate, $\mathrm{pH} 7.4 ; 100 \mathrm{mM}$ $\mathrm{NaCl} ; 1 \mathrm{mM}$ ethylenediamine-tetraacetic acid; $1 \mathrm{mM}$ ethyleneglycol-tetraacetic acid; $1 \%$ Triton X-100; 10\% glycerol; $0.1 \% \mathrm{SDS} ; 20 \mathrm{mM} \mathrm{Na}{ }_{4} \mathrm{P}_{2} \mathrm{O}_{7} ; 2 \mathrm{mM}$ sodium-orthovanadate, $\mathrm{Na}_{3} \mathrm{VO}_{4} ; 1 \mathrm{mM} \mathrm{NaF} ; 2 \mu \mathrm{g} / \mathrm{mL}$ aprotinin; $1 \mathrm{mM}$ phenylmethylsulfonyl fluoride; and $1 \mu \mathrm{g} / \mathrm{mL}$ leupeptin), centrifuged at $4{ }^{\circ} \mathrm{C}$ for 20 minutes at $12,000 \mathrm{rpm}$. The concentrations of NGF in the supernatants were determined by the use of an enzyme-linked immunosorbent assay kit following the instructions provided by the manufacturer (NGF Emax Immunoassay System; Promega, Madison, WI).

\section{Statistical Analysis}

All statistical evaluations were performed using the StatView package for Windows. The data are expressed as means \pm SEM. A $P$ value of less than 0.05 was considered significant. Post-hoc comparison within logical sets of means was performed using Tukey test.

\section{RESULTS}

\section{EIOP After Hypertonic Saline Injection}

Figure 1 shows the globes with the episcleral vein (arrow; Fig. 1A) and the site of injection (Fig. 2B) of hypertonic saline with a glass microneedle. As shown in Figure $1 \mathrm{C}$, injection of hypertonic saline leads to elevation of IOP, reaching greatest increase 7 days postinjection $(42.7 \pm 3.7 \mathrm{~mm} \mathrm{Hg}$ as compared with $26.9 \pm 2.6 \mathrm{~mm} \mathrm{Hg}$ of $\mathrm{CV}$ ), and remained elevated for the following 7 weeks. Ocular administration of NGF has no effect on IOP.

\section{NGF and RGC Distribution in Glaucomatous Untreated and NGF-treated Eyes}

Figure 2A reports the concentration of NGF in the retina with and without EIOP of NGF-treated and untreated rats. The level of NGF in the GLV retina decreased compared with baseline levels, at 7 weeks after induction of IOP (from $89 \pm 8.5$ to $62 \pm 5.2 \mathrm{pg} / \mathrm{g} ; P<0.05$ ). Ocular administration of NGF to glaucomatous eye (GLNGF) for 7 weeks enhanced retinal NGF levels (from $84 \pm 8.0$ to $151 \pm 21.3 \mathrm{pg} / \mathrm{g} ; P<0.01)$. An increase in retinal NGF was also found in the control retina treated with NGF (CNGF; from $85 \pm 10$ to $139 \pm 10.5 \mathrm{pg} / \mathrm{g} ; P<0.05$ ).

Histologic analysis of the retina shows cell loss in the retinal ganglion layer after hypertonic saline injection: GLV (Fig. 2C) compared with CV (Fig. 2B). Ocular administration of NGF for 7 consecutive weeks prevented RGC loss in GLNGF (Fig. 2D). Quantitative analyses indicate that EIOP causes nearly $50 \%$ loss of the RGCs and that after NGF treatment, this loss is less than $20 \%$ (Fig. 2E).

\section{The EIOP Causes Loss of NGF Receptors in RGCs}

Under normal conditions, RGCs of rats express TrkA and p75 NGF receptors (Figs. 3A, H). Seven weeks after induction of EIOP, the number of TrkA-positive RGCs decreases (Fig. 3B vs. Fig. 3A) and this decrease is prevented by ocular administration of NGF (Fig. 3C vs. Fig. 3B). As reported in Figure $3 \mathrm{E}$, these differences are statistically significant (GLV vs. CV: $* P<0.01$; GLNGF vs. GLV: $* * P<0.05)$. Moreover, results of western blotting analysis, shown in Figures $3 F$ and $G$, indicated that the TrkA protein expressed in the glaucomatous retina decreases and that NGF administration nearly prevented this decrease.

Figure 3 reports also the effect of EIOP on the expression of $\mathrm{p} 75$ receptor by RGCs. EIOP reduces the number of p75-positive cells (Fig. 3I vs. Fig. 3H) and this decrease is prevented by ocular NGF administration (Fig. 3L vs. Fig. 3I). As reported in Figure 3N, both the decrease of $\mathrm{p} 75$ expression in glaucomatous retina and the protective effect of NGF administration are statistically significant (GLV vs. CV: ${ }^{*} P<0.01$; GLNGF vs. GLV: $* * P<0.05)$. Western blotting analysis, shown in Figures $3 \mathrm{O}$ and $P$, showed that the $\mathrm{p} 75$ protein present in the retina decreases in glaucomatous retina and that this decrease is nearly prevented by ocular NGF administration.

\section{NGF Ocular Administration Prevents Apoptotic RGC Death}

To assess whether the reduced RGCs number was due to cell death, we next investigated the expression of biomarkers involved in cell death and cell survival. The RGCs of rats with EIOP are markedly stained by TUNEL (arrows in Fig. 4B), a biomarker of cell death, and are 

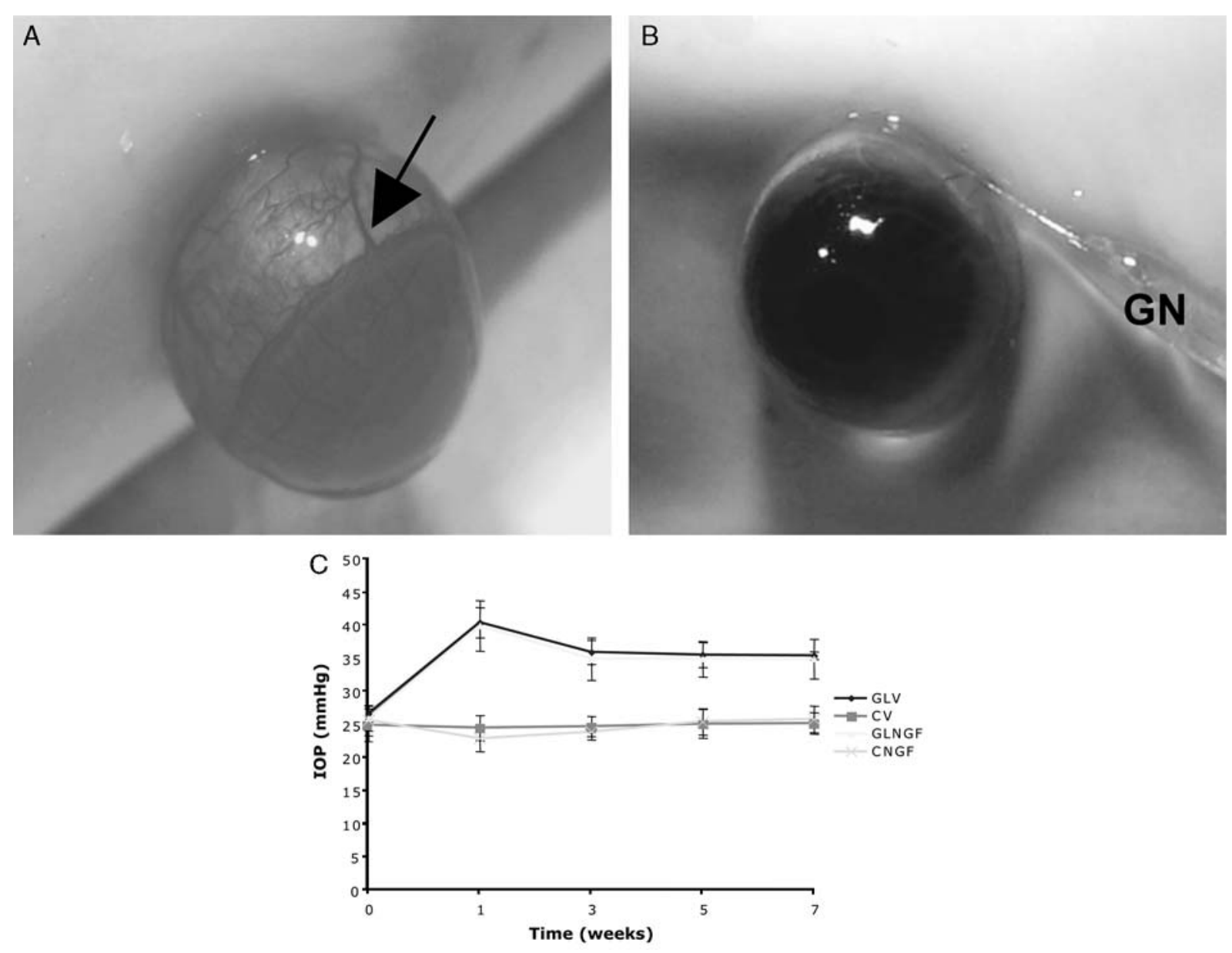

FIGURE 1. Representative microphotographs showing the episcleral vein (arrow) of rat eyes (A), the site of insertion of the glass microneedle $(\mathrm{GN})$ in the episcleral vein (B), and the time-course IOP of rats injected and non-injected with hypertonic saline (C). As reported in this figure, the injection of hypertonic saline in the episcleral vein causes a significant elevation of IOP as compared with control, reaching peak after 1 week $(P<0.01)$. As indicated, nerve growth factor $(N G F)$ eye administration is unable to normalize the IOP. CNGF indicates control eye treated with NGF; CV, control eye treated with vehicle solution; GLNGF, glaucomatous eye treated with NGF; GLV, glaucomatous eye treated with vehicle solution; IOP, intraocular pressure.

absent in control retina (Fig. 4A) and nearly absent in NGF-treated retinas (Fig. 4C). Quantitative analysis reported in Figure 4D revealed that the effect of NGF in preventing RGC apoptotic death is statistically significant $(P<0.01)$.

\section{NGF Administration Reduces the Number of Degenerating ON Axons Induced by EIOP}

Figure 5 shows representative electron microscopic sections of normal (Fig. 5A), glaucomatous (Fig. 5B), and NGF-treated glaucomatous (Fig. 5C) ON of a rat 7 weeks after induction of EIOP. As indicated by arrows, the ON of glaucomatous NGF-untreated rat shows degenerating axon profiles, characterized by varicosities or swelling, vacuolization, debris, and also signs of degenerating cells, most probably oligodendrocytes, nearly absent in the control and NGF treated axons. Quantitative determination reported in Figure 5D indicates that these differences are statistically significant $(P<0.01)$.

\section{DISCUSSION}

Using a rat model of GL induced by EIOP, we have investigated the role of $\mathrm{NGF}$ on damaged RGCs and ON axons. The results show that EIOP causes a transient local increase of NGF in the retina, followed by a significant decreases leading ultimately to RGC death through apoptotic mechanisms. We found that EIOP causes loss of RGCs, degeneration of ON axons, and a significant reduction of NGF, associated with a marked lower expression of low and high NGF-receptor by RGCs. EIOP causes a significant increase of TUNEL staining by RGCs, suggesting that degeneration of RGCs occurs through apoptotic mechanisms. These changes are markedly reduced by daily administration of eye NGF application, suggesting that NGF can protect the progressive degeneration of RGCs induced by EIOP.

Moreover, this study revealed that NGF delivered as eye drops protects RGCs and $\mathrm{ON}$ axons from degeneration and this noninvasive delivering method exerts its protective action in the absence of side effects. These observations support and extent earlier findings that NGF 


\section{A}

Concentration of NGF protein $(\mathrm{pg} / \mathrm{g})$ in the retina of glaucomatous and non-glaucomatous rats under different experimental conditions.

\begin{tabular}{|c|c|c|c|c|}
\hline \multirow[b]{2}{*}{ Treatment } & \multicolumn{3}{|c|}{ Weeks after treatment } & \\
\hline & 0 & 1 & 3 & t \\
\hline $\mathrm{CV}$ & $87 \pm 8.5$ & $86 \pm 9.2$ & $89 \pm 7.5$ & $94 \pm 8.3$ \\
\hline CNGF & $85 \pm 10$ & $117 \pm 11.9$ & $116 \pm 10.4$ & $139 \pm 10.5$ \\
\hline GLV & $89 \pm 8.5^{*}$ & $98 \pm 7.5^{*}$ & $104 \pm 7.0^{*}$ & $62 \pm 5.2^{* * *}$ \\
\hline GLNGF & $84 \pm 8.0^{\S}$ & $112 \pm 9.9^{\S}$ & $137 \pm 12.7 \S$ & $151 \pm 21.3^{* * *}$ \\
\hline
\end{tabular}

$\mathrm{CV}=$ non-glaucomatous eye treated with vehicle; $\mathrm{CNGF}=$ non-glaucomatous eye treated with $\mathrm{NGF}$; $\mathrm{GLV}=$ glaucomatous eye treated with vehicle; GLNGF=glaucomatous eye treated with NGF. Data are the average \pm S.E.M. of 5 samples in each experimental group. $* * \mathrm{p}<0.01$ compared to $* ; * * \mathrm{p}<0.01$ compared to $\$$.
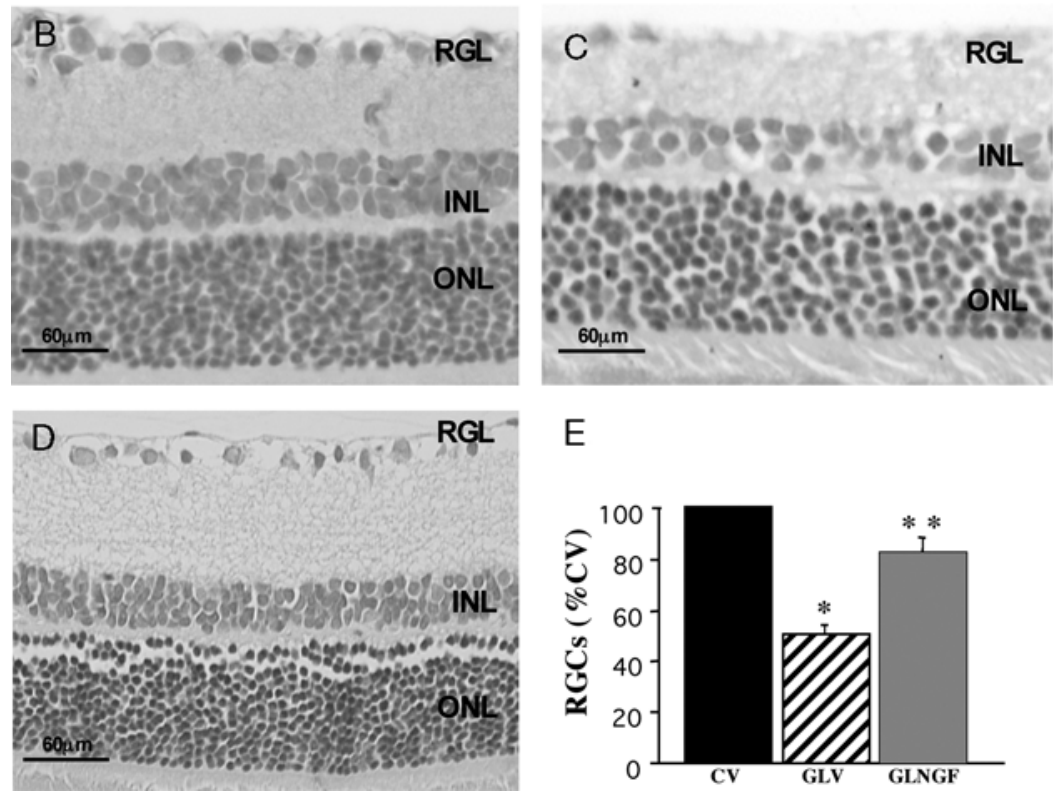

FIGURE 2. Time-course changes and statistic comparison between the end of treatment ( $7 \mathrm{wk})$ and 0 to 3 weeks reported in horizontal orientation. The concentration of NGF increases in the retina of glaucomatous retina (GLV) during the first 3 weeks ( $89 \pm 8.5,98 \pm 7.3$ vs. $104 \pm 7.0)$, thereafter the levels of NGF decreased significantly (62 \pm 5.2 vs. $104 \pm 7.0)$. In the glaucomatous retina treated with NGF (GLNGF), the level of NGF is elevated throughout the NGF treatment. An increase in NGF was also found in the retinas of normal rats treated with NGF (CNGF). Representative microscopic fields of normal (B), glaucomatous (C), and glaucomatous NGF-treated retinas (D), stained with hematoxylin-eosin showing the 3 retinal layers, the retinal ganglion layer (RGL), inner retinal layer (INL), and the outer retinal layer (ONL). Note that 7 weeks after hypertonic saline injection, the EIOP causes a marked decrease in the number of RGCs in the glaucomatous retina, compared with control retina. Quantitative evaluation (E) indicates that EIOP causes a statistically significant decrease in the number of RGCs compared with the control retina, whereas ocular administration of NGF largely prevented this decreases ( ${ }^{*} P<0.01$ compared to $C V$, and ${ }^{* *} P<0.05$ compared to GLV). B to D, Scale bars: $60 \mu \mathrm{m}$. EIOP indicates elevated intraocular pressure; NGF, nerve growth factor; RGCs, retinal ganglion cells.

and NGF receptors play a critical protective action on RGCs. ${ }^{15-17,20,21}$ More specifically, they indicate that shortage of NGF combined with abnormal expression of NGF-receptors are important key events that can lead to progressive RGC degeneration in GL and that NGF ocular administration can reduce or prevents these deleterious effects.
The critical role of NGF and its receptors in cell survival and cell death are supported by a number of other studies demonstrating that the biologic effect of NGF is mediated by competition between the low-affinity p75 receptor and the high-affinity TrkA receptor ${ }^{31}$ and the number of NGF-receptive RGCs can be critically dependent on such feedback loop. This dynamic mechanism 
regarding the role of NGF and/or NGF-receptor interaction can occur also in diabetic NGF-responsive cells. For example, recent studies showed that NGF supplementation produces significant changes in NGF-receptor expression, leading to a 19-fold increase in TrkA/p75. ${ }^{32,33}$
The role of NGF on retinal cells has been suggested by a number of other earlier and recent findings. Thus, intraocular administration of NGF has been shown to reduce rat $\mathrm{RGC}$ degeneration after $\mathrm{ON}$ lesion, ${ }^{14}$ in rabbit ocular hypertension, ${ }^{19}$ and in rats with inherited retinopathy. ${ }^{17}$ It has
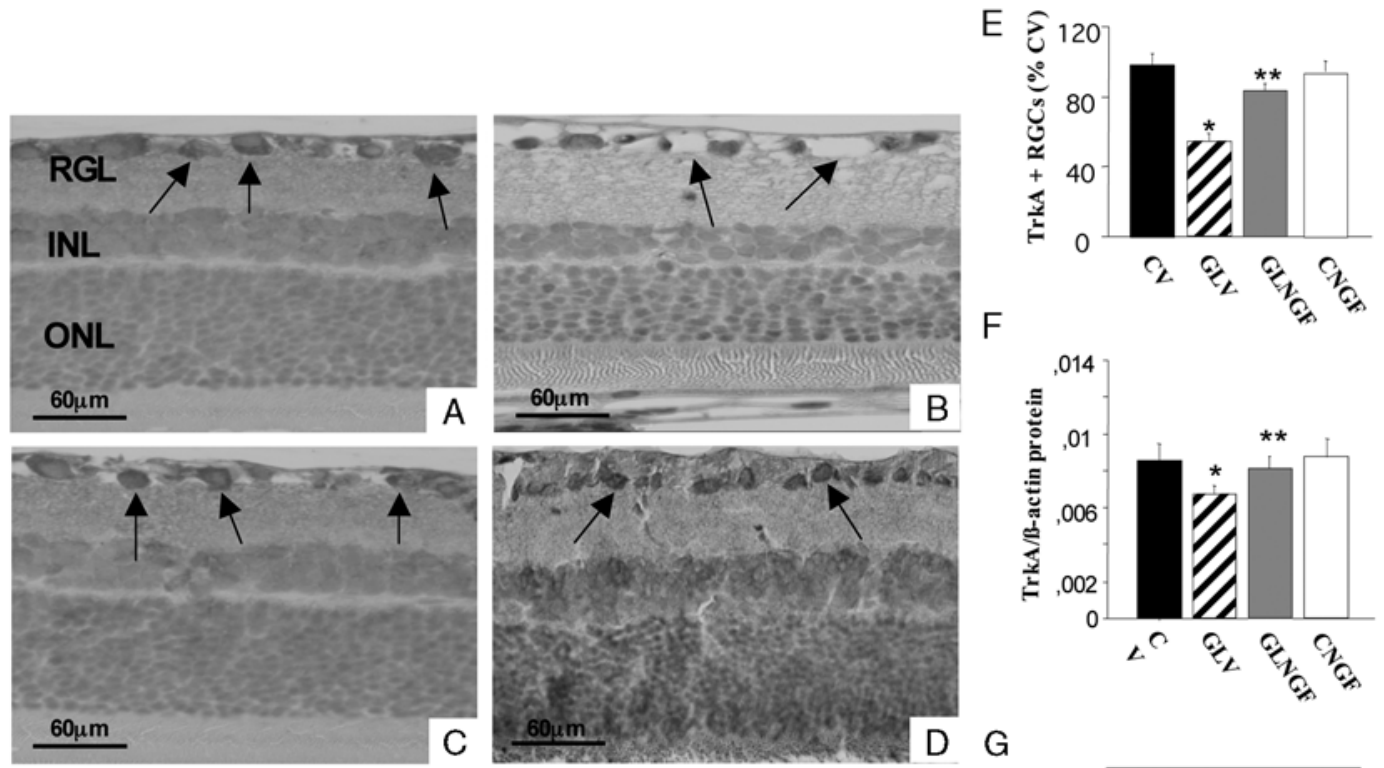

G
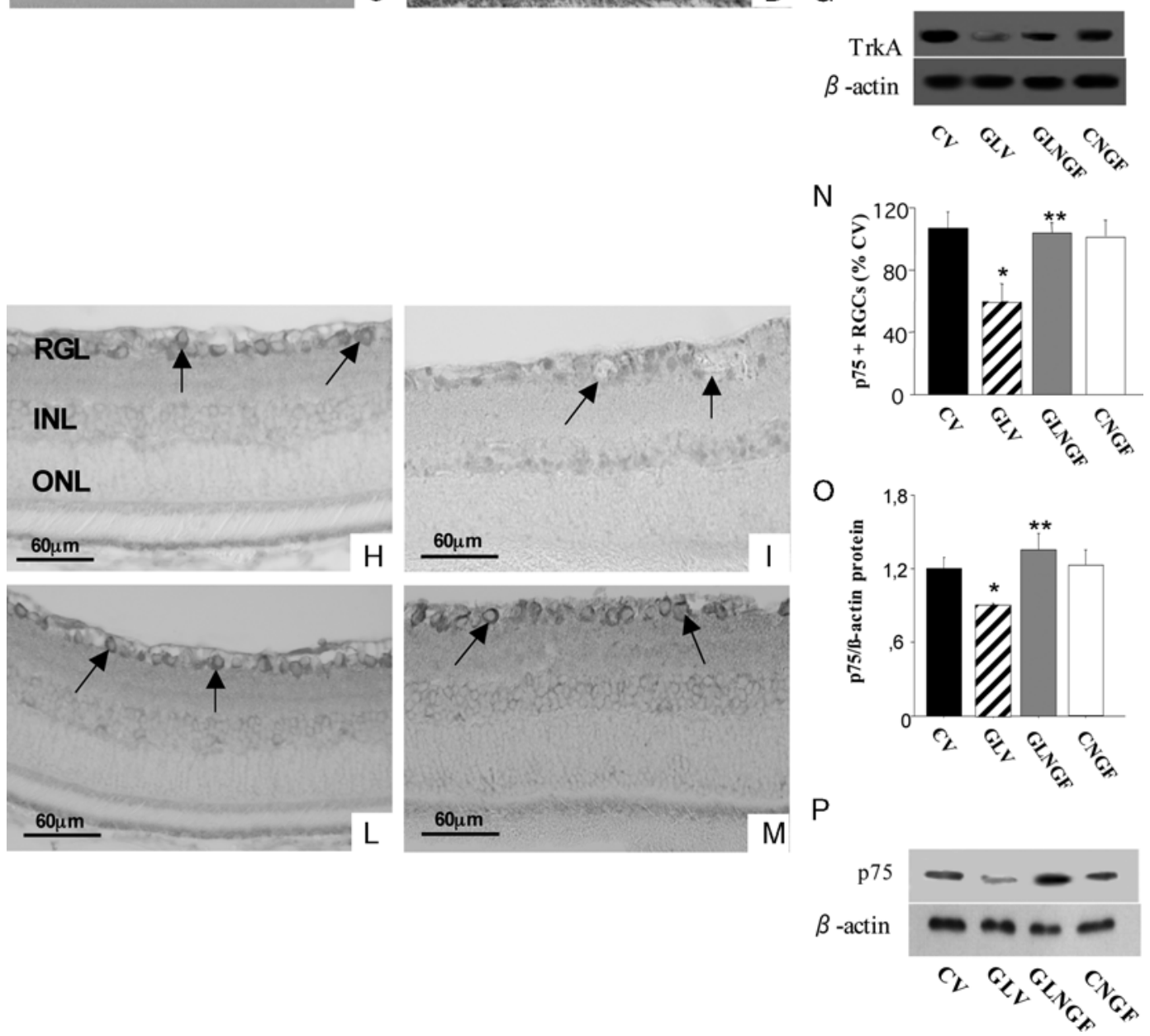

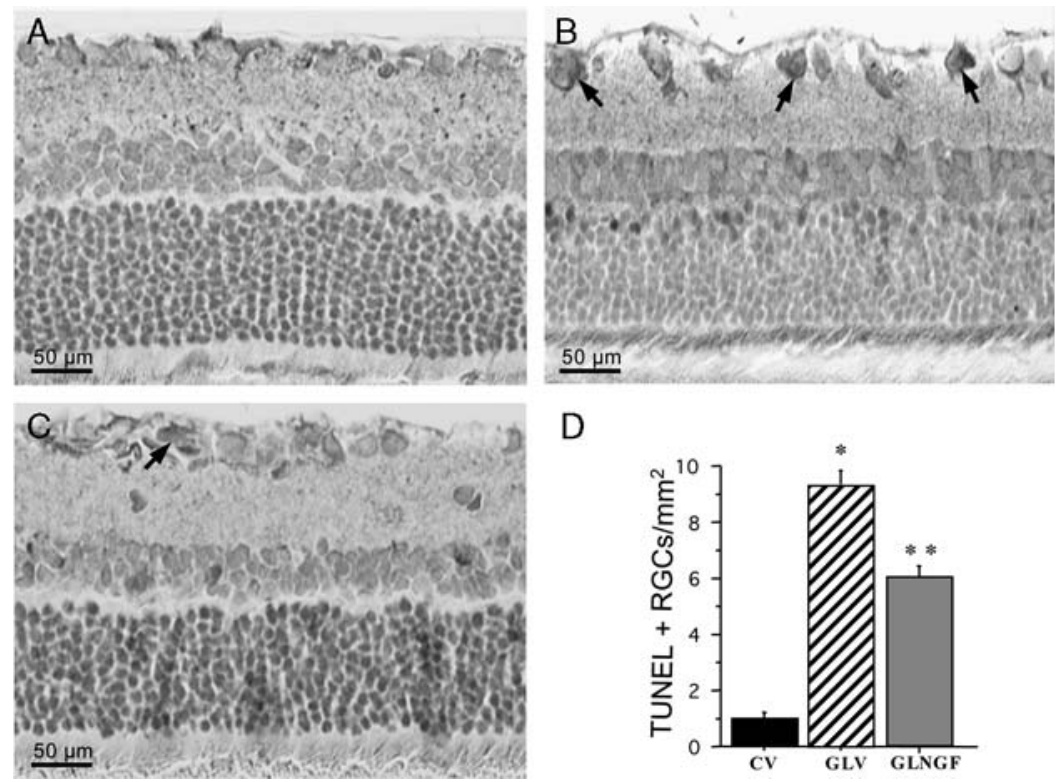

FIGURE 4. Representative retinal sections of control (A), glaucomatous (B), and glaucomatous eyes treated with NGF (C) stained by TUNEL, a marker for cell death. Note the presence of TUNEL-positive retinal ganglion cells (RGCs) (arrows) in glaucomatous eyes compared with control and glaucomatous eyes treated with NGF. TUNEL-positive cells in the retinal ganglion layer of glaucomatous eyes are indicated with arrows. These differences are statistically significant $(D){ }^{*} P<0.01$ vs. control eye treated with vehicle solution $(\mathrm{CV}) ;{ }^{* *} P<0.05$ vs. glaucomatous eye treated with vehicle solution (GLV)]. A to C, Scale bars: $50 \mu \mathrm{m}$. GLNGF indicates glaucomatous retina treated with NGF; NGF, nerve growth factor; TUNEL, terminal deoxynucleotidyl transferase-mediated deoxyuridine triphosphatebiotin nick-end labeling.

been reported that administration of high molecular weight protein to the ocular surface can reach the retina and brain neurons through ${ }^{34,35}$ and that topical ocular administration of NGF can be a noninvasive approach to deliver NGF to the posterior portion of the eye and into the brain. These latter studies have demonstrated the protective role of eye NGF application on retinal cells not only in laboratory animals, ${ }^{36-38}$ but also in humans. ${ }^{39}$ Indeed, in a recent observation in 3 patients with progressive visual-field defects and severe abnormalities in photopic electroretinogram and visual evoked potential responses and dysfunction of the innermost retinal layers, ocular NGF application improved mean visual field defects in 2 patients, and stabilized the defect in the third patient. Improvement of visual field persisted 90 days after discontinuation of treatment, indicating that changes induced by NGF had a long-lasting effect. ${ }^{39}$

Recently, studies by Rudzinski et $\mathrm{al}^{40}$ and Shi et $\mathrm{al}^{41}$ performed in animal model of ocular hypertension or GL lead to the hypothesis that neither NGF nor antagonist of the proapoptotic p 75 protect damaged RGC. Our results are somehow in contrast with their findings. Why our findings are different is not clear. We believe, based also on the available data that these differences can be because of: (a) the different animal model of GL we used; (b) the time and dose of NGF treatment; and (c) a more detailed structural and biochemical analysis or a combination of (a), (b), and (c). Moreover, it should be also taken into

FIGURE 3. Expression of TrkA and p75 receptors in retina of rats with EIOP treated and untreated with NGF. Representative microscopic fields of TrkA-immunostained control (A), glaucomatous (B), glaucomatous NGF-treated (C), and non-glaucomatous NGF-treated (D) in the RGL. These immunostained preparations indicate a reduced presence of TrkA-positive RGCs (arrows) in rats with ElOP (B), compared with controls (A) and that ocular NGF administration nearly prevented this reduction (C). Quantitative analysis (E) revealed that the decrease of TrkA-positive cells in glaucomatous retina and the effect on NGF are statistically significant ${ }^{*} P<0.01$ vs. CV; ${ }^{* *} P<0.05$ vs. GLV). Western blotting analysis of TrkA protein expressed in the glaucomatous retina treated and untreated with NGF, compared with their controls $(F$ and $G$ ). The result indicates that TrkA protein decreases in glaucomatous retina and NGF administration in glaucomatous retina reduces this deficit $\left({ }^{*} P<0.01\right.$ vs. $C V ;{ }^{* *} P<0.05$ vs. GLV). Representative microscopic fields of $p 75$-immunostained control $(\mathrm{H})$, glaucomatous (I), glaucomatous NGF-treated (L), and non-glaucomatous NGF-treated (M) in the RGL. These immunostained preparations revealed a decreased expression of p75-positive RGCs (arrows) in rats with EIOP (I), compared with controls (H) and that ocular NGF administration nearly prevented this reduction $(\mathrm{L})$. Quantitative analysis $(\mathrm{N})$ revealed that the decrease of p75-positive cells in glaucomatous retina and the effect on NGF are statistically significant $\left({ }^{*} P<0.01\right.$ vs. CV; ${ }^{* *} P<0.05$ vs. GLV). Western blotting analysis of p75 protein expressed in the glaucomatous retina treated and untreated with NGF, compared with their controls $(\mathrm{O}$ and $\mathrm{P})$. The data obtained indicates that $\mathrm{p} 75$ protein decreases in glaucomatous retina and NGF administration in glaucomatous retina reduces this effect $\left({ }^{\star} P<0.01\right.$ vs. $C V ;{ }^{*} P<0.05$ vs. GLV). A to $\mathrm{D}$ and $\mathrm{H}$ to $\mathrm{M}$ scale bars: $0.03 \mu \mathrm{m}$. CNGF indicates control eye treated with NGF; CV, control eye treated with vehicle solution; EIOP, elevated intraocular pressure; GLNGF, glaucomatous retina treated with NGF; GLV, glaucomatous eye treated with vehicle solution; INL, inner retinal layer; NGF, nerve growth factor; ONL, outer retinal layer; RGCs, retinal ganglion cells; RGL, retinal ganglion layer. 

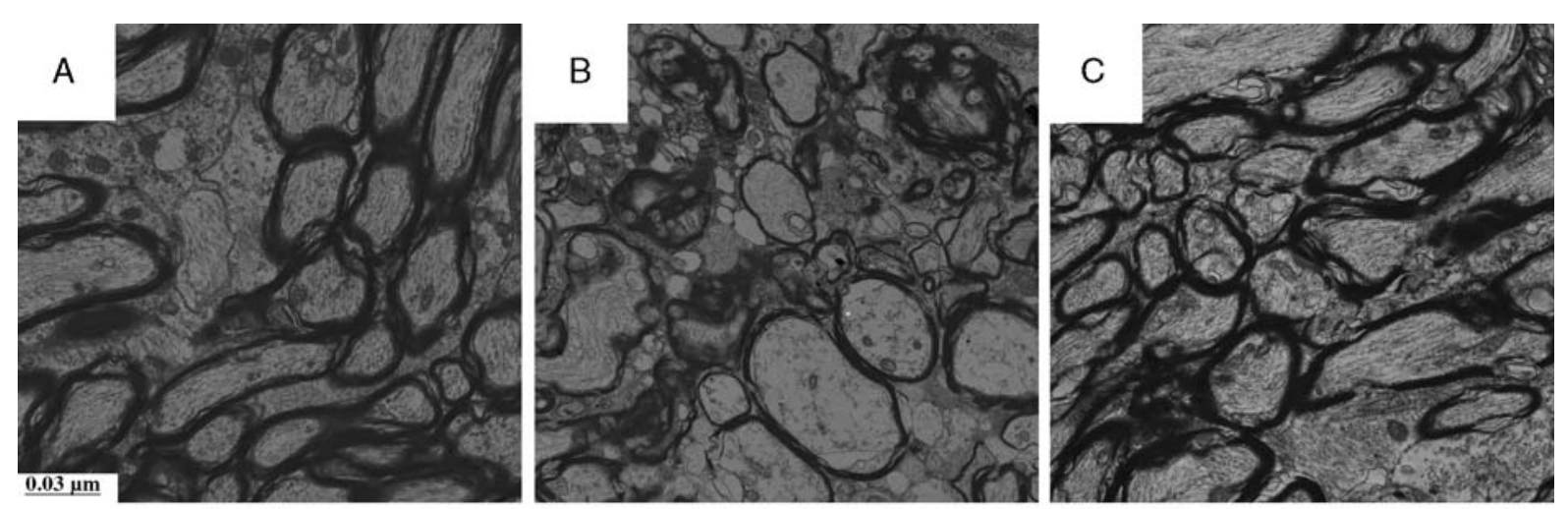

$\mathrm{D}$

\begin{abstract}
Axons of the optic nerve of control (CV), glaucomatous treated with vehicle (GLV) and glaucomatous treated with NGF (GLNGF) rats showing degenerative profiles, as revealed by ultrastructural analysis
\end{abstract}

type of treatment

ON section/rat

Area/section/ $/ \mu \mathrm{m} 2$

40000

40000

40000

\author{
degenerating \\ profile/area
}

\author{
$15.0 \pm 7.3$ \\ $230.0 \pm 15.4 * *$ \\ $60.0 \pm 5.4 *$
}

**p $<0.01$ compared to $\mathrm{CV}$ and $* \mathrm{p}<0.05$ to $\mathrm{CV}$

FIGURE 5. Representative electron-microscopic sections of control (A), glaucomatous untreated (B), and glaucomatous NGF-treated ON (C), 7 weeks after the induction of elevated intraocular pressure. Note retinal ganglion cell axons in the ON of glaucomatous eye (B) showing varicosities, swellings, and vacuolization (arrows), compared with control ON (A). In the glaucomatous ON treated with NGF, these degenerating signs are greatly reduced or nearly absent $(C)$. These differences are statistically significant $(D)\left({ }^{*} P<0.01\right.$ vs. $C V$; ${ }^{* *} P<0.01$ vs. GLV). A to $C$ scale bars: $0.03 \mu \mathrm{m}$. NGF indicates nerve growth factor; ON, optic nerve.

consideration that NGF has been shown to protect damaged RGCs after ON section, ${ }^{14}$ after ocular ischemia, ${ }^{16}$ ocular hypertension, ${ }^{40}$ and inherited retinitis pigmentosa. ${ }^{17}$

A key question raised by our observations is the mechanism through which NGF administration protects RGCs without lowering the IOP. The evidence that patients with low IOP still experience visual loss, and others with GL and ON degeneration display normal IOP, ${ }^{4,5}$ suggests that the EIOP might not be the only mechanism through which RGCs degenerate. Thus, changes in the neuronal environment, such as a neurotransmitter imbalance, influx of calcium into the cells, formation of free radicals, and depletion of growth factors can take part in retinal degeneration and RGC damages induced by elevated IOP. This hypothesis is suggested by observation after systemic application of brimonidine, ${ }^{42}$ chondroitin sulphate proteoglycan, ${ }^{43}$ or memantine, an $N$ methyl-D-aspartate open channel blocker. ${ }^{44}$ On the basis of the available data that RGCs are highly receptive to NGF, a reasonable hypothesis is that the ocular NGF application reaches the posterior segment of the eye bindings to retinal cells and renders more resistant RGCs to the damage induced by EIOP. Moreover, the possibility that NGF can exert its action through other growth factors, including brainderived neurotrophic factor, cannot be excluded..$^{18,25}$

In summary, our data suggest that the reduced presence of NGF and the loss of NGF receptors in retinal cells is an important step in the progression of GL. The reduction of degenerative events in RGCs and ON after ocular NGF application suggests that NGF represents a possible useful molecule for GL by protecting RGC death and $\mathrm{ON}$ axon loss.

\section{ACKNOWLEDGMENT}

The authors thank the English editing of the American Journal Experts, Durham, NC, USA.

\section{REFERENCES}

1. Quigley HA. Number of people with glaucoma worldwide. $\mathrm{Br}$ J Ophthalmol. 1996;80:389-393.

2. Levin LA. Retinal ganglion cells and neuroprotection for glaucoma. Surv Ophthalmol. 2003;48(suppl 1):S21-S24.

3. Weinreb RN, Khaw PT. Primary open-angle glaucoma. Lancet. 2004;363:1711-1720.

4. Sommer A. Intraocular pressure and glaucoma. Am J Ophthalmol. 1989;107:186-188.

5. Kuehn MH, Fingert JH, Kwon YH. Retinal ganglion cell death in glaucoma: mechanisms and neuroprotective strategies. Ophthalmol Clin North Am. 2005;18:383-395, vi.

6. Guo L, Moss SE, Alexander RA, et al. Retinal ganglion cell apoptosis in glaucoma is related to intraocular pressure and IOP-induced effects on extracellular matrix. Invest Ophthalmol Vis Sci. 2005;46:175-182.

7. Schwartz M. Lessons for glaucoma from other neurodegenerative diseases: can one treatment suit them all? J Glaucoma. 2005;14:321-323. 
8. Hartwick AT. Beyond intraocular pressure: neuroprotective strategies for future glaucoma therapy. Optom Vis Sci. 2001;78: 85-94.

9. Levi-Montalcini R. The nerve growth factor 35 years later. Science. 1987;237:1154-1162.

10. Connor B, Dragunow M. The role of neuronal growth factors in neurodegenerative disorders of the human brain. Brain Res Brain Res Rev. 1998;27:1-39.

11. Aloe L, Calzá L, eds. NGF and Related Molecules in Health and Disease. Amsterdam: Elsevier; 2004:544.

12. Casaccia-Bonnefil P, Gu C, Chao MV. Neurotrophins in cell survival/death decisions. Adv Exp Med Biol. 1999;468:275-282.

13. Meakin SO, Shooter EM. The nerve growth factor family of receptors. Trends Neurosci. 1992;15:323-331.

14. Carmignoto G, Maffei L, Candeo P, et al. Effect of NGF on the survival of rat retinal ganglion cells following optic nerve section. J Neurosci. 1989;9:1263-1272.

15. Rabacchi SA, Ensini M, Bonfanti L, et al. Nerve growth factor reduces apoptosis of axotomized retinal ganglion cells in the neonatal rat. Neuroscience. 1994;63:969-973.

16. Siliprandi R, Canella R, Carmignoto G. Nerve growth factor promotes functional recovery of retinal ganglion cells after ischemia. Invest Ophthalmol Vis Sci. 1993;34:3232-3245.

17. Lenzi L, Coassin M, Lambiase A, et al. Effect of exogenous administration of nerve growth factor in the retina of rats with inherited retinitis pigmentosa. Vision Res. 2005;45:1491-1500.

18. LaVail MM, Unoki K, Yasumura D, et al. Multiple growth factors, cytokines, and neurotrophins rescue photoreceptors from the damaging effects of constant light. Proc Natl Acad Sci U S A. 1992;89:11249-11253.

19. Lambiase A, Centofanti M, Micera A, et al. Nerve growth factor (NGF) reduces and NGF antibody exacerbates retinal damage induced in rabbit by experimental ocular hypertension. Graefes Arch Clin Exp Ophthalmol. 1997;235:780-785.

20. Lambiase A, Aloe L. Nerve growth factor delays retinal degeneration in $\mathrm{C} 3 \mathrm{H}$ mice. Graefes Arch Clin Exp Ophthalmol. 1996;234(suppl 1):S96-S100.

21. Mey J, Thanos S. Intravitreal injections of neurotrophic factors support the survival of axotomized retinal ganglion cells in adult rats in vivo. Brain Res. 1993;602:304-317.

22. Hallbook F, Bäckström A, Kullander K, et al. Expression of neurotrophins and trk receptors in the avian retina. J Comp Neurol. 1996;364:664-676.

23. Oku H, Ikeda T, Honma $\mathrm{Y}$, et al. Gene expression of neurotrophins and their high-affinity Trk receptors in cultured human Muller cells. Ophthalmic Res. 2002;34:38-42.

24. García M, Forster V, Hicks D, et al. In vivo expression of neurotrophins and neurotrophin receptors is conserved in adult porcine retina in vitro. Invest Ophthalmol Vis Sci. 2003; 44:4532-4541.

25. Lambiase A, Tirassa P, Micera A, et al. Pharmacokinetics of conjunctivally applied nerve growth factor in the retina and optic nerve of adult rats. Invest Ophthalmol Vis Sci. 2005;46: 3800-3806.

26. Lambiase A, Pagani L, Di Fausto V, et al. Nerve growth factor eye drop administrated on the ocular surface of rodents affects the nucleus basalis and septum: biochemical and structural evidence. Brain Res. 2007;1127:45-51.

27. Di Fausto V, Fiore M, Tirassa P, et al. Eye drop NGF administration promotes the recovery of chemically injured cholinergic neurons of adult mouse forebrain. Eur J Neurosci. 2007;26:2473-2480.
28. Morrison JC, Moore CG, Deppmeier LM, et al. A rat model of chronic pressure-induced optic nerve damage. Exp Eye Res. 1997;64:85-96.

29. Bocchini V, Angeletti PU. The nerve growth factor: purification as a 30,000-molecular-weight protein. Proc Natl Acad Sci U S A. 1969;64:787-794.

30. Sun X, Jin K, Xie L, et al. Effects of nerve growth factor for retinal cell survival in experimental retinal detachment. Curr Eye Res. 2007;32:765-772.

31. Casaccia-Bonnefil P, Kong H, Chao MV. Neurotrophins: the biological paradox of survival factors eliciting apoptosis. Cell Death Differ. 1998;5:357-364.

32. Salis MB, Graiani G, Desortes E, et al. Nerve growth factor supplementation reverses the impairment, induced by type 1 diabetes, of hindlimb post-ischaemic recovery in mice. Diabetologia. 2004;47:1055-1063.

33. Graiani G, Emanueli C, Desortes E, et al. Nerve growth factor promotes reparative angiogenesis and inhibits endothelial apoptosis in cutaneous wounds of type 1 diabetic mice. Diabetologia. 2004;47:1047-1054.

34. Ambati J, Canakis CS, Miller JW, et al. Diffusion of high molecular weight compounds through sclera. Invest Ophthalmol Vis Sci. 2000;41:1181-1185.

35. Koevary SB. Pharmacokinetics of topical ocular drug delivery: potential uses for the treatment of diseases of the posterior segment and beyond. Curr Drug Metab. 2003;4:213-222.

36. Sposato V, Bucci MG, Coassin M, et al. Reduced NGF level and TrkA protein and TrkA gene expression in the optic nerve of rats with experimentally induced glaucoma. Neurosci Lett. 2008;446:20-24.

37. Sposato V, Parisi V, Manni L, et al. Glaucoma alters the expression of NGF and NGF receptors in visual cortex and geniculate nucleus of rats: effect of eye NGF application. Vision Res. 2009;49:54-63.

38. Coassin M, Lambiase A, Sposato V, et al. Retinal p75 and bax overexpression is associated with retinal ganglion cells apoptosis in a rat model of glaucoma. Graefes Arch Clin Exp Ophthalmol. 2008;246:1743-1749.

39. Lambiase A, Aloe L, Centofanti M, et al. Experimental and clinical evidence of neuroprotection by nerve growth factor eye drops: implications for glaucoma. Proc Natl Acad Sci U S A. 2009;109:13469-13474.

40. Rudzinski M, Wong TP, Saragovi HU. Changes in retinal expression of neurotrophins and neurotrophin receptors induced by ocular hypertension. J Neurobiol. 2004;58:341-354.

41. Shi Z, Birman E, Saragovi HU. Neurotrophic rationale in glaucoma: a TrkA agonist, but not NGF or a p75 antagonist, protects retinal ganglion cells in vivo. Dev Neurobiol. 2007;67: 884-894.

42. WoldeMussie E, Ruiz G, Wijono M, et al. Neuroprotection of retinal ganglion cells by brimonidine in rats with laser-induced chronic ocular hypertension. Invest Ophthalmol Vis Sci. 2001;42: 2849-2855.

43. Bakalash S, Rolls A, Lider O, et al. Chondroitin sulfatederived disaccharide protects retinal cells from elevated intraocular pressure in aged and immunocompromised rats. Invest Ophthalmol Vis Sci. 2007;48:1181-1190.

44. Hare W, WoldeMussie E, Lai R, et al. Efficacy and safety of memantine, an NMDA-type open-channel blocker, for reduction of retinal injury associated with experimental glaucoma in rat and monkey. Surv Ophthalmol. 2001;45(suppl 3): S284-S289. 